\title{
Museus de memória traumática na América Latina: uma leitura arquitetônica com base na emoção e na experiência
}

Traumatic memory museums in Latin America: an architectural reading based on emotion and experience Ivo Giroto*

*Professor do Departamento de História da Arquitetura e Estética do Projeto da Faculdade de Arquitetura e Urbanismo da Universidade de São Paulo - FAU USP. Pós-doutor pela FAU USP/FAPESP (2017/2020), e Mestre (2008) e Doutor em Teoria e História da Arquitetura (2014) pela ETSAB UPC, em Barcelona. Pesquisador do Observatório de Arquitectura Latinoamericana Contemporánea - ODALC, e do grupo Arquitetura e Cidade Moderna e Contemporânea da FAU USP. Investiga temas relacionados à cultura urbana e à arquitetura moderna e contemporânea no Brasil e na América Latina, com ênfase na produção de equipamentos culturais, igiroto@gmail.com

\section{Palavras-chave:}

Museus de memória.

Arquitetura emocional.

Museologia sensorial.

\section{Keywords:}

Memorial museums.

Emotional architecture.

Sensory museology.

\begin{abstract}
Resumo Abstract
a arquitetura, em par com a museografia, é mobimemoria traumática na América Latina. Investiga como a conjuração entucional e de suas formas de representação, são capazes de gerar uma experiência induzida por uma narrativa construída sobre a memória histórica. Enfoca as estratégias emocionais utilizadas em dois museus situtorica. Enfoca as estrategias emocionais utilizadas em dois museus situados nas antípodas do subcontinente e que abordam diferentes memo-
rias traumáticas: o chileno Museo de la Memoria y los Derechos Humanos e o mexicano Museo Memoria y Tolerancia. Debate os objetivos, potencialidades e limites da exploração emocional em relação ao que a maioria dessas instituições declara como missão: instituir espaços em que a cultura dos direitos humanos e dos valores democráticos se conAbstract vertam em fundamento ético compartilhado, de forma a que as violências

The article examines how architecture, in tandem with museography, is used to emotionally activate visitors in museums dedicated to traumatic memory in Latin America. It investigates how the conjuration between the characteristics of the site where they are located, the institutional purpose and its forms of representation, are capable of generating an experience induced by a narrative built about historical memory. It focuses on the emotional strategies used in two museums located in the antipodes of the subcontinent and that address different traumatic memories: the Chilean Museo de la Memoria y los Derechos Humanos and the Mexican Museo Memoria y Tolerancia. It debates the objectives, potentialities and limits of emotional exploration in relation to what most of these institutions declare as mission: to establish spaces in which the culture of human rights and democratic values become a shared ethical foundation, so that the violence addressed does not happen again.
\end{abstract}


Em agosto de 2018, o Ministro da Cultura chileno Mauricio Rojas viu-se obrigado a pedir demissão apenas quatro dias após assumir o cargo, depois de vir a público uma declaração feita três anos antes, na qual considerava que o Museu da Memória e dos Direitos Humanos de Santiago era uma narrativa montada com o propósito de impactar o espectador, deixá-lo atônito e impedi-lo de raciocinar através de uma "dasavergonhada" manipulação histórica de uma tragédia nacional, qual seja, a sistemática violação de direitos humanos durante a ditadura de Augusto Pinochet.

Se por um lado a polêmica declaração expõe a filiação ideológica do efêmero ministro, por outro coloca em pauta o caráter seletivo inerente a todo museu do gênero. De fato, trata-se de uma equação complexa: como abordar de forma equilibrada violações de direitos humanos em conflitos que dividem sociedades, como no caso das ditaduras latino-americanas do século XX?

A construção narrativa dos museus memoriais sempre pode ser alvo de críticas e questionamentos, mas parte de fatos históricos, documentos e objetos reais. Se há diversas formas de historicizar e musealizar as memórias traumáticas, as violações de direitos humanos não são passíveis de contestação. Nas palavras da presidenta Michelle Bachellet, em seu discurso de inauguração do museu de Santiago em 11 de janeiro de 2010, a tragédia pode ter muitas explicações, mas nenhuma justificação (BACHELET, 2010, p. 2).

A controversa declaração do então ministro chileno representa uma persistente defesa ou relativização da atuação de regimes autoritários por parte de numerosas parcelas das sociedades latino-americanas. Pode ainda ser considerada como parte das reações ao debate público aberto pelas investigações levadas à cabo pelas diversas comissões nacionais instauradas para esclarecer os abusos e violações de Estado, que na América Latina remontam ao princípio dos anos 1980 em diversos países e, muito tardiamente, no Brasil apenas em 2012.

Ao buscar reconstituir a verdade por meio da confrontação de diversos testemunhos e documentos históricos, o farto material produzido pelo trabalho dessas comissões encontra na instauração de museus e memoriais um dos meios preferenciais de acesso público a documentos oficiais, fotos, vídeos, objetos e notícias de imprensa, contribuindo para que seus objetivos centrais sejam alcançados: a promoção da justiça histórica, a reparação simbólica e psicológica das vítimas, e a reconciliação social, a fim de que eventos traumáticos não tornam a ocorrer.

Como observa Beatriz Sarlo (2005, p. 46), depois do fim das ditaduras na América do Sul, lembrar foi um ato de restauração dos vínculos sociais e comunitários transtornados pelo terrorismo de Estado. A partir de meados dos anos 1980, a coincidência entre a restauração local da ordem democrática com um novo impulso no discurso intelectual e ideológico sobre o Holocausto na Europa, especialmente na Alemanha, potencializaram fatos significativos que inevitavelmente entrelaçaram os dois debates. Nesse contexto, o Holocausto surge como modelo para todos os demais crimes - assim como as políticas instituídas de reparação e monumentalização de tragédias-, uma vez que a necessidade de condenação a um crime contra a humanidade se sobrepõe a aspectos nacionais específicos.

De fato, desde então os memoriais ao Holocausto têm se espalhado pelas mais diversas nações do mundo. Porém, como ressalta o eminente estudioso de museus Paul Williams, os memoriais a outros tipos de crimes contra direitos humanos que vieram na sequência tendem a se localizar em países que efetivamente testemunharam determinados eventos traumáticos (WILLIAMS, 2007, p. 132). É o caso da América Latina, onde as instituições de maior visibilidade social estão relacionadas às violações de direitos humanos perpetradas pelos Estados nacionais ao longo do século XX, com especial ênfase ao período entre 1960 e 1990, ao longo do qual vigoraram brutais ditaduras cívico-militares em diversos países do continente.

Parte da comoção suscitada por essas instituições deve-se à condição de tocarem em "nervos expostos" da sociedade, trabalhando sobre a "História do tempo presente", definição que Pierre Nora faz do período contemporâneo "[...] segundo uma linha que separa a História hoje vivida da História hoje morta" (1993, p. 52).

Trata-se, portanto, de museus nos quais a rigorosidade histórica dos fatos expostos inevitavelmente se associa a uma forte dimensão emocional. Não pretendem ser espaços onde impera o distanciamento analítico exigido pela História, ao contrário, são monumentos responsáveis por reavivar um passado através da imersão afetiva, fazendo-o vibrar como se fosse presente (CHOAY, 2017, p. 21). 
A questão é importante pois à diferença da maioria dos museus, especialmente os históricos, essas instituições não buscam fazer uma reconstituição da história, mas explorar a dimensão da memória, o que é sensivelmente distinto. Como assevera Nora (1993, p. 9), a memória carreia dimensões afetivas e simbólicas que pertencem ao universo experiencial, o que a diferencia da operação intelectual das abordagens tradicionais da história.

Não é objetivo deste artigo esmiuçar os significados e conceitos atribuídos à memória - nem tampouco ao seu par antitético, a amnésia e o direito ao esquecimento-, aos quais têm se dedicado inúmeros autores do campo das ciências sociais (CONNERTON, 1989, 2009; ARNOLD-DE-SIMINE, 2013; HALBWACHS, 2013; LE GOFF, 1990; NORA, 1984; POLLAK, 1989; RICOEUR, 2007, TODOROV, 2013). Tão somente serão alvo de algum aprofundamento certas definições à medida em que servirão de suporte às análises pretendidas, que têm como objeto aspectos da arquitetura e da museologia neste tipo de instituição, cujo aumento numérico e de visibilidade nas últimas décadas tem sido alvo de diversos estudiosos, seja no âmbito mais geral do objeto rememorado (ARANTES, 1993; BRESCIANI \& NAXARA, 2004; CUNDY \& PÖRGZEN, 2016; HOWES, 2014; HUYSSEN, 2000) ou no campo específico das memórias traumáticas, tanto em âmbito global (GREENBERG, 2010; HANSEN-GLÜCKLICH, 2016; WILLIAMS, 2007; STURKEN, 2011, 2015), quanto latino-americano (CABRAL, 2019; CYMBALISTA, 2019; CONSIDERA, 2015; LIFSCHITZ, 2014; MENESES, 2018; MORA, 2013; TORRE, 2006; SILVESTRI, 2000).

Este artigo pretende contribuir ao debate iluminando um ponto específico acerca dos museus dedicados a memórias traumáticas na América Latina que, salvo meIhor juízo, ainda tem sido pouco explorado. Trata-se de indagar como a arquitetura, em par com a museografia, é mobilizada para ativar emocionalmente os visitantes, a ponto de gerar uma experiência de visitação induzida pela narrativa construída sobre a memória histórica no museu.

Para além dessa questão de fundo, propõe-se debater os objetivos, potencialidades e limites da exploração emocional em relação ao que a maioria dessas instituições declara como missão: instituir espaços em que a cultura dos direitos humanos e dos valores democráticos se convertam em fundamento ético compartilhado, de forma a que as violências abordadas não voltem a acontecer.

\section{Analisar com base na emoção e na experiência}

Um museu memorial, conforme observa Ulpiano Bezerra de Meneses (2018, p. 6), tem entre suas principais aptidões a capacidade de articular o cognitivo e o afetivo, sendo a museografia responsável por acionar ao extremo o potencial emotivo dos museus, nos quais a arquitetura comumente se converte em peça introdutória do ethos específico de cada um.

Muito comum na arquitetura e na expografia de museus de memória, a exploração da dimensão emocional dos visitantes compreende um ainda incipiente campo de estudos aberto pela repercussão das premissas da Nova Museologia a partir dos anos 1980, quando à concepção tradicional de museu como instituição que adquire, conserva, investiga, comunica e expõe passou-se a reconhecer também a validade de estratégias emocionais e experienciais, alterando o entendimento da própria natureza e da função institucional (CUNDY; PORZGEN, 2016, p. 359).

Por emoção, entende-se qualquer estado, movimento ou condição que provoque em um sujeito a percepção do valor que determinada situação tem para sua vida, suas necessidades, seus interesses (ABAGNANO, 1970). Derivada do latim motio.onis, a emoção também carrega a denotação de movimento, de deslocamento. É neste sentido que Ulpiano Bezerra de Meneses considera (2018, p. 7) que o museu tem entre seus objetivos, para além de transmitir conhecimento e informação, tocar emocionalmente os indivíduos, movê-los, empurrá-los à ação.

Em paralelo e complementarmente à ativação das emoções, David Howes (2014, p. 259-260) identifica nas últimas décadas uma atenção crescente de estudiosos de diversas áreas das humanidades pelo universo sensorial, desafiando o monopólio da psicologia na área, o que para os museus pode significar um ganho na percepção dos objetos e histórias narradas. Nesse tipo de "museologia sensorial", a hegemonia do sentido da visão deve dividir espaço com a introdução de recursos táteis, gustativos, olfativos e auditivos, transformando o espectador em participante. Howes elenca entre as razões para sua defesa da exploração sensorial em museus algo visto com estranheza pelos museus atuais: o propósito de cura, física e espiritual, prática com origens no toque a relíquias e amuletos que não era inusual em museus do século XVII e XVIII. 
Em museus memoriais, o movimento pendular entre cura espiritual e conscientização coletiva revela o complexo entrelaçamento entre o ser individual e o ser social que reside no conceito de memória coletiva de Maurice Halbwachs, para quem a memória pessoal é sempre construída em grupo, sem deixar ao mesmo tempo de ser um trabalho de articulação própria do sujeito (HALBWACHS, 2013, p. 30-39).

A concepção de Halbwachs de que a memória se apega mais ao fato vivido e percebido que a racionalizações ou explicações científicas dialoga com a abordagem fenomenológica da percepção. Com efeito, Merleau-Ponty define a fenomenologia como um relato do espaço, do tempo e do mundo vividos, e uma tentativa de descrição direta de nossa experiência (MERLEAU-PONTY, 2011, p. 1).

A filósofa estadunidense Martha Nussbaum (2008, p. 21-23) contrapõe à ideia generalizada da emoção como algo irracional uma dimensão de inteligência e discernimento que não deve ser ignorada ao se levar a cabo um juízo ético. Segundo sua argumentação, a explicação teórica das emoções tem profundas consequências para a teoria da razão prática, bem como para as relações entre ética e estética, e afirma que o ponto de partida de uma investigação de tipo cognitivo-avaliadora deve ser a análise da experiência.

De forma geral, ao enfatizar o processo pelo qual a dimensão perceptiva se transforma em experiência da consciência, a fenomenologia aparece como pilar teóricometodológico central a uma análise que propõe destacar aspectos emocionais e experienciais, ainda que não prescinda de aproximações de ordem semiótica e reconheça a importância dos signos para a análise da arquitetura de museus do gênero. Parece coerente, portanto, que uma leitura deste tipo lance mão de uma crítica baseada em condições emotivas ou aureáticas, que evidenciem o uso de estratégias arquitetônicas sensoriais, perceptivas e metafóricas (RAMÍREZ NIETO, 2011).

Trata-se, portanto, de uma apreciação crítica do autor sobre as estratégias mobilizadas por arquitetos, curadores e museógrafos. Neste ponto, difere de leituras amparadas por estudos empíricos feitos com visitantes, baseadas no cotejamento das apropriações sociais das narrativas e símbolos trabalhados pelos museus, abordagem específica que tem sido objeto de diversas pesquisas e leituras (LAVIELLE, 2020; BASTÍAS SEKULOVIC, 2017).
Assim como há diversas possibilidades de análise, também a exploração emocional pela museografia e pela arquitetura apresenta táticas variadas, todas equilibrandose em limites tênues e escorregadios. Estudiosos como Alison Landsberg defendem que as reações provocadas nos visitantes podem, através do "lugar experiencial" criado pelo museu, fazer com que um indivíduo tome a narrativa histórica de forma pessoal, através de uma memória profundamente sentida de um passado que possivelmente não tenha vivido, ou seja, por meio da configuração de uma memória vicária, ou "protética" (LANDSBERG, p. 2004). Este tipo de memória substituta encontra sentido e expressão no que Nora definiu como lugares de memória, um conceito amplo que tem como pressuposto a coexistência de aspectos materiais, funcionais e simbólicos, ligados por uma "vontade de memória" (NORA, 1993, p. 2122).

No êxito da articulação entre estes aspectos reside a capacidade de ativar memórias em um lugar ou edifício, que por si só não é capaz de conjurar. Para uma análise arquitetônica, é possível relacionar os aspectos da vontade de memória de Nora a três características que Susana Torre (2006, p. 18) identifica como condições para que uma estrutura seja mais ou menos efetiva em ativar as reinscrições da memória: o sítio, o propósito e a representação.

\section{Sítio, propósito e representação}

Segundo Torre (ibidem), quando um monumento ou museu ocupa o mesmo lugar dos eventos comemorados, a conexão entre sítio e significado é direta, sendo ele o próprio monumento. São os casos do Memorial da Resistência de São Paulo (2009), instalado em um edifício que entre 1942 e 1983 sediou delegacias vinculadas ao Departamento Estadual de Ordem Política e Social de São Paulo - Deops; do Espacio Memoria y Derechos Humanos de Buenos Aires (2015), em um conjunto de edifícios militares da antiga Escuela de Mecánica de la Armada - ESMA que foram cenários de crimes durante a ditadura cívico-militar argentina (1976-1983); ou do Sitio de Memoria de Montevidéu (2018), que ocupa um imóvel onde funcionou a sede do Serviço de Informação da Defesa, órgão estatal usado como centro clandestino de detenção na ditadura uruguaia (Figura 1). 


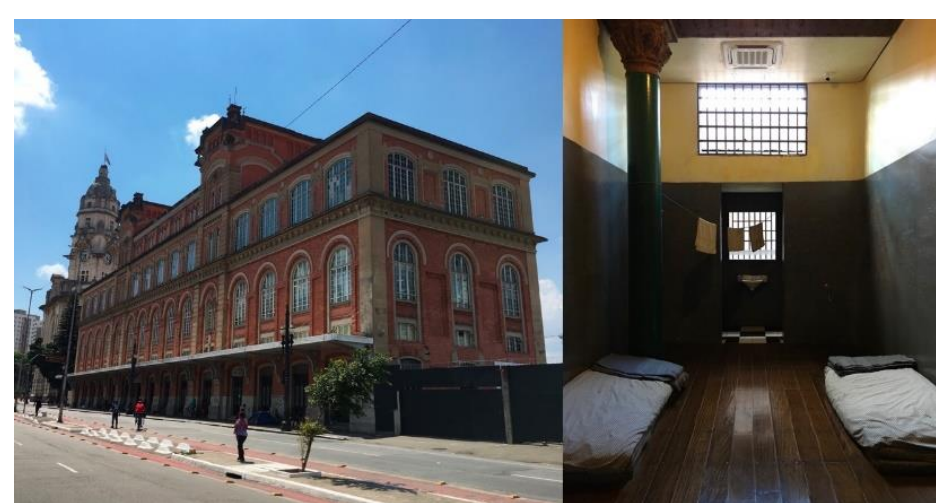

Figura Erro! Nenhuma sequência foi especificada.. Memorial da Resistência, São Paulo. Foto: Ivo Giroto (montagem), 2020

Todos estes exemplos abordam preferencialmente o terrorismo de Estado na segunda metade do século passado, temática norteadora da maioria dos museus de memória traumática latino-americana ${ }^{1}$. Nesses museus, a condição de documento histórico das edificações tende a resultar em intervenções arquitetônicas mínimas, que não alteram sua estrutura original. As narrativas museológicas procuram explorar a impressão de realidade ou participação nos visitantes a partir da reconstituição de espaços onde os eventos ocorreram, e a emotividade é acionada a partir do caráter de testemunha que muitas vezes aproxima o edifício/sítio da dimensão solene de um templo ou de uma tumba simbólica.

O propósito, por sua vez, responde à necessidade de criar espaços para o luto, o reconhecimento público do sofrimento e um permanente alerta social para que um determinado crime não torne a ocorrer. Está diretamente relacionado à definição do programa e ao tema abordado por cada museu (idem, p. 19).

A definição de qual evento traumático, e a partir de que ponto de vista será tratado, também influem na dinâmica de apropriação intelectual e recepção perceptiva que conduz a experiência dos visitantes. Efetivamente, a proximidade ou distanciamento histórico, geográfico, cultural e pessoal em relação ao tema conduzem a leituras

${ }^{1}$ Somente a Rede Latino-americana e do Caribe de Sítios de Memória (RESLAC) reúne 44 instituições em 12 países que tratam de violações de direitos humanos na região, em especial sobre terrorismo de Estado e conflitos armados internos. afetivas diversas em instituições como o Museo de la Memoria y de los Derechos Humanos- MMDH (2010), de Santiago, e o Museo Memoria y Tolerancia - MyT (2010), na Cidade do México. Enquanto o museu chileno toca na questão universal dos Direitos Humanos através de um trauma nacional, o terrorismo de Estado praticado pelo regime do ditador Pinochet entre 1973 e 1990, o mexicano parte de uma tragédia que possui impacto planetário, o Holocausto judeu - ainda que tenha tido como palco central a Alemanha e seu entorno-, para alcançar genocídios localizados em diversos países e continentes.

Finalmente, a representação, que Torre define como os desenhos e linguagens visuais empregados para comunicar as ideias que constituem o propósito principal de um monumento (idem, p. 21).

Inúmeros outros casos e possibilidades poderiam ser levantados e discutidos, a partir da diversidade presente nos museus do gênero na América Latina. Há, inclusive, condições peculiares, em que um novo edifício é construído sobre um terreno prenhe de memórias, não necessariamente relacionadas ao tema que se quer colocar em questão, como o Centro de Memoria, Paz y Reconciliación, projeto de Juan Pablo Ortiz (2013) erigido em homenagem às vítimas do persistente conflito armado na Colômbia sobre um cemitério histórico de Bogotá, o que exigiu a exumação de mais de três mil ossadas.

Caso, em certa medida, comparável ao de instituições como o Museu de la Memoria - MUME de Montevidéu (2007), que ao enfatizar os crimes ocorridos durante a ditadura uruguaia deixa em segundo plano a importância histórica de uma mansão senhorial de 1878, construída pelo ditador do século XIX Máximo Santos, ou do Museu dos Direitos Humanos do Mercosul (2011), em Porto Alegre, que secundariza a história do prédio projetado em 1923 para abrigar a sede dos Correios e Telégrafos. $O$ próprio Memorial da Resistência paulistano é lugar de cruzamentos e obliterações de memórias, já que pouco se identifica da história do prédio, originalmente projetado por Ramos de Azevedo em 1914 para abrigar os armazéns da antiga Estrada de Ferro Sorocabana. 
Em quaisquer dos casos mencionados seria possível identificar convergências e descompassos entre as narrativas de sítio, propósito e representação. No entanto, em edifícios novos, onde essa conjuração é construída livre de preexistências físicas e históricas, a participação de arquitetos e museógrafos é mais evidente. Por isso, com ênfase na identificação de estratégias emocionais, e norteada pela trinca de condicionantes proposta por Susana Torre, segue uma análise da interação entre arquitetura e museografia em dois museus situados nas antípodas da América Latina e que abordam diferentes memórias traumáticas: o chileno MMDH e o mexicano MyT.

\section{MMDH E MYT: dialéticas da memória}

Em 1953, Mathias Goeritz publicava seu Manifesto da Arquitetura Emocional, que servia como memorial justificativo de seu projeto para o Museu Experimental El Eco, na Cidade do México. Opondo-se ao ascetismo racionalista moderno, acreditava que a arquitetura deveria ser expressão das mais altas inquietudes espirituais do homem, buscando a integração plástica para causar uma máxima emoção (GOERITZ, 2015).

Em que pese o pioneirismo do uso do termo por Goeritz, que junto a Luis Barragán colocou a ideia de uma arquitetura emocional no centro de sua pesquisa teórica e estética, o conceito é polissêmico e há muito tem sido apropriado de diversas formas por muitos arquitetos e em variados lugares do planeta. Não se trata de cercar aqui definições precisas, mas apontar para o fato de que a exploração de formas, materiais, texturas, luzes e sombras, sons e aromas, tem marcado boa parte da produção da arquitetura contemporânea, a exemplo da abordagem fenomenológica presente no trabalho de arquitetos como Juani Pallasma ou Peter Zumthor, entre muitos outros.

Referência inescapável na exploração de estratégias emocionais na arquitetura de museus de memória, o Museu Judaico de Berlim, de Daniel Libeskind (1989-1999), estabelece uma estrutura narrativa baseada na criação de uma série de cenografias metafóricas que impõem ao visitante uma experiência densa e incômoda. Ao contrário, a maioria dos novos museus e memoriais latino-americanos parece ter optado por outro tipo de experiência, evitando explorar sensações aflitivas em favor de espacialidades que sugerem reflexão através de ambientes luminosos e espacialmente integrados.
No Lugar de la Memoria, la Tolerancia y la Inclusión Social - LUM (2013), voltado à violência sofrida pelos peruanos nos conflitos entre grupos terroristas e o Estado desde os anos 1980, os arquitetos Sandra Barclay e Jean-Pierre Crousse declaram como objetivo da arquitetura criar um lugar onde pessoas de diversas origens políticas e sociais possam, coletivamente, alcançar o caminho da reconciliação (BARCLAY \& CROUSSE, 2015) (Figura 2).

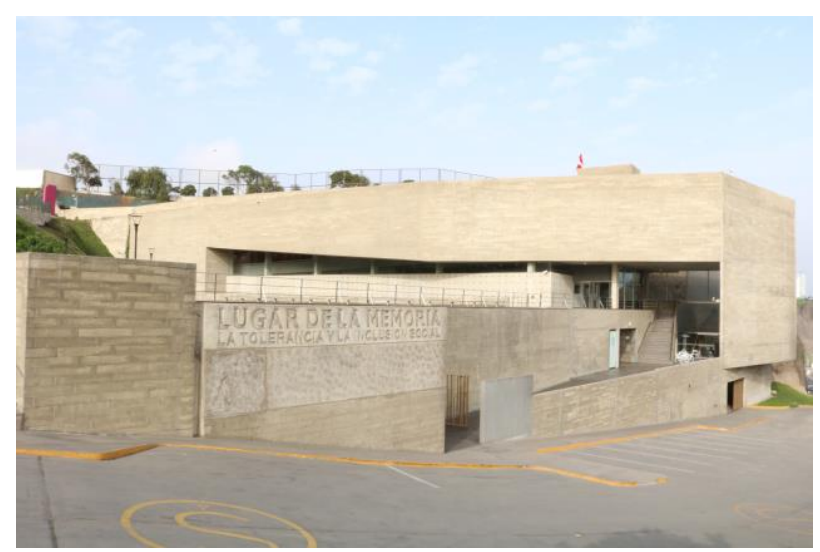

Figura 2. Lugar de la Memoria, la Tolerancia y la Inclusión Social, Lima. Disponível em https://search.creativecommons.org/photos/4bbdf542-b4d2-44ae-ae55-24b38cc379e8. Acesso em: 20 mar 2021.

Para tanto, o museu cria um percurso ascendente que liga os diferentes níveis de um penhasco, reconstruindo a geografia original através de uma sucessão de falhas e fraturas que sugerem, a um só tempo, a ideia de fragmentação e de conexão social, de rompimento e sutura, e que culmina em uma tranquilizante vista aberta ao Oceano Pacífico. A fusão volumétrica e cromática com o terreno não deixa de ser uma forma de livrar o edifício da responsabilidade de metaforizar de forma mais contundente o tema do museu, ao deslocar a representação em direção à memória da paisagem.

Por sua vez, o Museo Casa de la Memoria (2011), construído em Medellín para tratar da violência generalizada da qual a cidade foi palco nas últimas décadas do século XX, define uma arquitetura linear que, na definição do arquiteto Juan David 
Botero, se desdobra como um túnel que visa a criação de sensações em uma metafórica rota de transição da escuridão da morte à luz da esperança (BOTERO, 2015).

A intenção de gerar uma trajetória, conduzida por estreitos e altos corredores inclinados que conectam os dois diferentes níveis do terreno, não fica exatamente legível aos visitantes, também pelo fato de que a museologia propõe um percurso livre, sem ordem específica para deambular pelas salas de exposição, o que rompe a ideia de um caminho linear com início e fim.

No entanto, este museu representa uma classe de instituição fortemente relacionada e eventos traumáticos locais, sendo a maioria dos visitantes da própria cidade, o que interfere diretamente na recepção emocional aos fatos abordados (LAVIELLE, 2020, p. 13) ${ }^{2}$. (Figura 3)

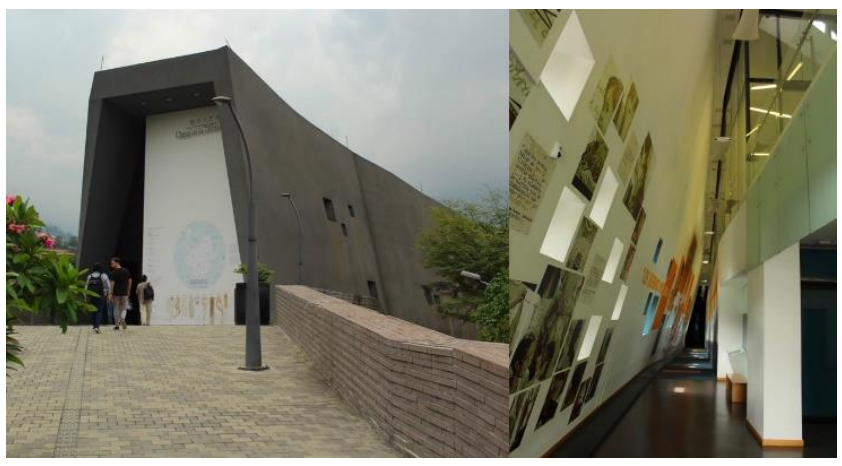

Figura 3. Museo Casa de la Memoria, Medellín. Foto: Ivo Giroto (montagem), 2018.

No memorial do projeto vencedor do concurso para o Museo de la Memoria y de los Derechos Humanos - MMDH , os arquitetos Mario Figueroa, Lucas Fehr e Carlos Dias, então juntos no Estúdio América, ${ }^{3}$ evidenciam o desejo de representar uma memória que evita enfatizar a retrospectiva amarga, e prefere mirar em direção ao

${ }^{2}$ Segundo pesquisa feita por Julie Lavielle com visitantes do museu, $73 \%$ afirmam ter um vínculo com as temáticas abordadas, enquanto $20 \%$ dizem ter ligação direta com o conflito armado que assolou a região.

${ }^{3} \grave{A}$ equipe vencedora se associou o arquiteto chileno Roberto lbieta. futuro, sem perder a consciência do passado (FIGUEROA; FEHR; DIAS, 2010, p. $35)$.

Nas palavras de seu diretor Ricardo Brodsky Baudet (2015, p. 153), o MMDH não elude o dissenso político, ao contrário, assume que o que é controvertido na sociedade, também o deve ser no museu. Porém, declara que em seu esforço pedagógico, ao invés de abrumar as audiências com o horror, busca propiciar reflexões autônomas sem cair em manipulações históricas (Figura 4).

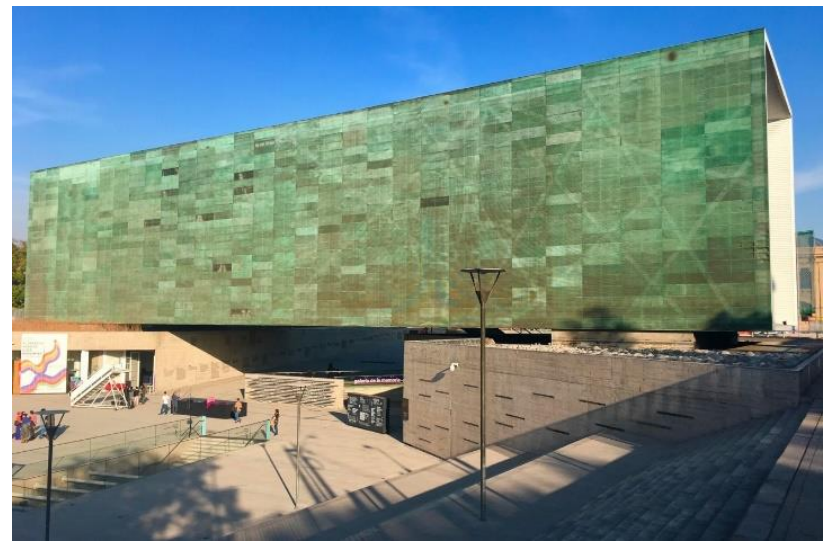

Figura 4. MMDH, vista exterior. Foto: Ivo Giroto, 2019

Implantado em um sítio neutro de Santiago, vizinho ao Parque novecentista Quinta Normal, o projeto cria uma praça semienterrada protegida do movimentado entorno, sobre a qual repousa transversalmente um volume prismático horizontal puro que conecta as laterais leste e oeste do terreno, dispondo-se transversalmente à conformação geográfica norte-sul do Chile, país cingido entre o Pacífico e os Andes . ${ }^{4}$

Referências ao cobre, ao carvão (carbono) e à terra chilena na materialidade do edifício, completam um jogo referencial fundamentado no uso de elementos neutros

${ }^{4} \mathrm{O}$ concurso foi lançado pelo Ministério de Obras Públicas em 2007, e contemplava para além do museu o Centro Matucana, que não foi construído, com prejuízos consideráveis à completude da quadra aberta desejada pelos arquitetos. 
e teoricamente livres de polêmica - os recursos naturais chilenos-, e não diretamente relacionados ao tema do museu. $O$ deslizamento da memória traumática para elementos vinculados a aspectos da identidade nacional trabalha para a criação de um campo simbólico consensual, que encontra guarida no fato de o museu integrar um conjunto de obras lançadas para comemorar o bicentenário da independência do Chile.

Ao telurismo que busca associar um povo aos recursos de sua terra, associa-se o imaginário da memória como algo etéreo, fugidio e emergente, materializado como uma grande arca "suavemente elevada", uma "pedra de cristal" íntegra e sublime (FIGUEROA; FEHR; DIAS, op. cit., p. 37-38). A dialética entre peso e leveza remete ainda a memórias de outra ordem: a menção aos monólitos flutuantes pintados por René Magritte, que por sua vez evocam a metafórica pedra no céu que Paulo Mendes da Rocha desenhou para o MUBE (1996), também criado a partir de uma operação topográfica que valoriza um corpo em aparente suspensão sobre uma praça seca.

A elegância da forma que nega seu peso ao evitar tocar o solo, e a bem-sucedida implantação urbana são grandes virtudes do projeto. Do ponto de vista urbano, na grande praça apropriada para a realização de comemorações, solenidades e operações não rotineiras que, segundo Nora (op. cit., p. 13), são responsáveis por enraizar no lugar as lembranças evocadas. Do ponto de vista arquitetônico, na delicada mediação entre interior e exterior estabelecida pela membrana de cobre que reveste o volume prismático, definindo a sensação corpórea e a sutileza entre ver e entrever que Peter Zumthor (2009, p. 22) reconhece entre as principais qualidades da arquitetura.

O museu é resolvido, funcional e conceitualmente, através de uma lógica bipartida entre barra - setor museográfico, flutuação das memórias- e base - setor museológico, penetração na terra, mineração (idem, p. 41). A aproximação ao objeto reforça essa estruturação, a começar pelo ritmo descendente conferido por amplas escadarias laterais e por uma grande rampa que parte do lado sul, como preparação à imersão proposta pelo museu. Uma vez sob o volume prismático, o percurso em direção às memórias passa a ser ascendente.

No interior do prisma, um espaço central revela a integração entre os três pavimentos do museu, bem como sua clara lógica estruturadora: três extensos espaços lineares longitudinais - um central para exposição e dois laterais, sendo um para circulação e outro para exposição e, principalmente, um pequeno volume cúbico envidraçado que se precipita sobre o vão central, posicionado de frente a uma grande superfície vertical, sobre a qual estão dispostas inúmeras fotografias de vítimas da ditadura (Figura 5).

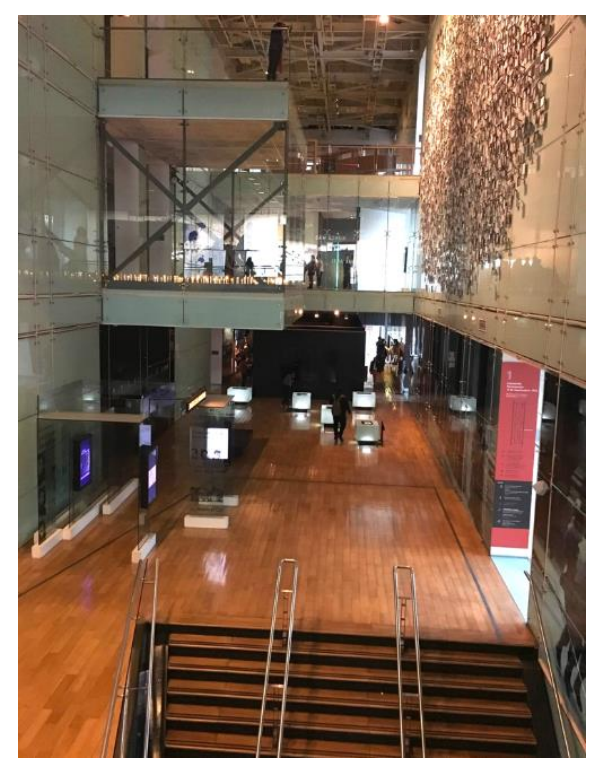

Figura 5. MMDH, vista do átrio central. Foto: Ivo Giroto, 2019.

Atributos comumente considerados positivos e que possibilitam uma rápida apreensão da totalidade do interior parecem, no entanto, contradizer a evocação que os arquitetos fazem da memória como um mundo inconcluso e fragmentário que, conforme deixam implícito, deveria ter rebatimento arquitetônico em um museu pensado a partir do caráter não linear do tempo e de suas imagens (FIGUEROA; FEHR; DIAS, idem).

No mesmo sentido, se há na implantação e na volumetria uma evidente relação com as estratégias projetuais de próceres da arquitetura moderna paulista, não se nota a mesma riqueza na exploração da luz e das sombras, nem das texturas e 
caraterísticas cromáticas dos materiais, que na obra de arquitetos como Mendes da Rocha atingem uma dimensão realmente fenomenológica (VILLAC, 2002, p. 349351).

Nos espaços expositivos principais do MMDH, a iluminação abundante - natural e artificial - reage com o brilho frio dos revestimentos e fechamentos em vidro verdeazulado e dos metais cromados dos acabamentos e proteções, resultando em uma ambientação pouco afeita ao recolhimento. Parece haver certa dissintonia entre a temperatura física e psíquica do espaço, que quando dialogam harmoniosamente resultam em edifícios pensados como uma massa de sombras, nos quais a luminosidade estrategicamente se infiltra e cria uma simbiose com os materiais (ZUMTHOR, op. cit., p. 60).

Estratégia emocional comum em museus de memória, a idealização de um ponto de grande carga simbólica faz interagir arquitetura, arte e museografia: o cubo de cristal que, assemelhado a uma capela, faz analogia aos tradicionais velatones, rituais de acender velas em homenagem aos mortos. Diretamente relacionada ao propósito do museu, a reflexão sugerida pela multidão de rostos desaparecidos que encaram o visitante é molestada pela luminosidade homogênea e a transparência antiaurática do vidro (Figura 6).

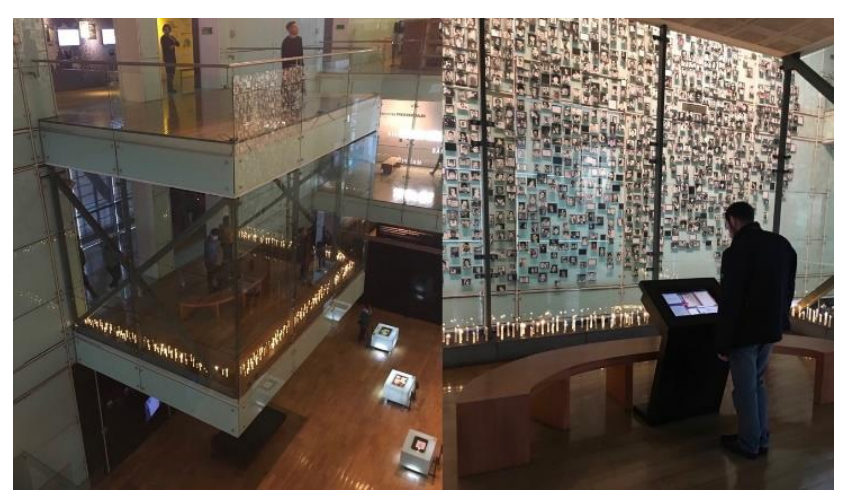

Figura 6. MMDH, vista do cubo envidraçado. Foto: Ivo Giroto (montagem), 2019.

Como observa Miguel Lawner Steiman (2010, p. 14), há nos interiores do MMDH uma onipresença luminosa, conferindo uma ambientação que pode até mesmo ser considerada "alegre", a seu juízo uma forma de reduzir as tensões geradas pela exibição de fatos tão traumáticos. Segundo os arquitetos, os amplos e iluminados espaços têm por objetivo metaforicamente lançar luz sobre a questão dos direitos humanos, torná-la transparente.

O fato é que a arquitetura do MMDH deliberadamente evita reportar-se ao trauma, procurando articular uma estrutura narrativa de unidade e otimismo, traduzida na leveza interna e externa da arquitetura. A atitude em favor de consensos, no entanto, não agradou a todos.

O historiador chileno Andrés Estefane, por exemplo, aponta para o fato de que o memorial do projeto não esclarece como o edifício responde ao seu propósito histórico. Ditadura, tortura e violência parecem ser palavras proibidas, cuja contundência é evitada em favor de referências às principais commodities do país (ESTEFANE, 2013, p. 161). Estefane argumenta que a opção dos arquitetos por desenhar espaços claros, leves, "alegres", discrepa da forma com que a museografia enfrenta o desafio de representar a violência de Estado, em que documentos, imagens, cartas, vídeos, depoimentos e obras de arte assumem o papel da ativação emocional, adentrando o terreno escorregadio que a arquitetura decide evitar.

Leitura corroborada por uma pesquisa realizada por Malena Bastías Sekulovic (2017), que atesta que a mensagem institucional é apreendida com clareza pela maioria dos visitantes, porém revela que a maioria já possuía conhecimentos ou algum engajamento com o tema, fazendo com que a visita tenha um caráter menos cognitivo e mais instrutivo-sensorial proporcionada pelos recursos midiáticos da museografia. No entanto, para a autora a eficiência da museografia na transmissão da narrativa institucional, ao reiterar a ideia consensual de condenação às violações de direitos humanos e reforçar um discurso de pacificação nacional, acaba por diluir a controvérsia e restringir os marcos de interpretação. (BASTíAS SEKULOVIC, 2017, p. 217).

No museu, diversas instalações e peças de arte feitas por artistas convidados como Jorge Tacla - Al mismo tempo, en el mismo lugar (2010) - e Alfredo Jaar - Geometría de la consciencia (2010) - igualmente procuram confrontar o passado difícil, sem necessariamente impingir ao visitante uma reencenação do trauma. A intervenção de Jaar estabelece uma especial relação com a arquitetura: localizada em uma pequena sala no subsolo, acessada pela praça e desconectada do museu, estimula 
nos visitantes um processo reflexivo ativado pelo jogo antagônico entre a luz e a escuridão, em meio ao qual resplandecem 500 silhuetas de chilenos, vítimas diretas e indiretas da ditadura, multiplicadas pelo efeito dos espelhos que recobrem a sala.

Com propósito semelhante, o Museo Memoria y Tolerancia - MyT aborda um tema de impacto universal, com ressonâncias indiretas no território latino-americano: 0 Holocausto judeu. Tecnicamente, não é um museu inteiramente dedicado ao genocídio hebreu, mas o coloca como peça central de uma exposição que abrange diversos episódios análogos ao longo do século passado.

Impulsionado por uma associação civil de membros da comunidade judia mexicana, o museu foi projetado por Mauricio Arditti e seus dois filhos, Arturo e Jorge, do Arditti + RDT Arquitectos, como parte do Proyecto Juárez $(2005)^{5}$, que interviu em uma quadra limítrofe ao centro histórico da Cidade do México, muito afetada pelo terremoto de 1985. Sob coordenação de Ricardo Legorreta, a intervenção dispôs novas edificações públicas ao redor da igreja colonial de Corpus Christi, uma das poucas estruturas que resistiram ao sismo.

Externamente, é melhor visto a partir da praça interna definida pelo terreno que circunda a igreja, sendo pouco visível pela face da congestionada Avenida Juárez. Não configura, portanto, o ícone urbano que caracteriza o volume solto no espaço do $\mathrm{MMDH}$, nem procura em sua volumetria ou materialidade fazer qualquer referência ao tema abordado em seu interior (Figura 7).

No MyT a organização programática se alinha à narrativa museográfica, evidenciando sua estrutura e os tempos da visita. O percurso é marcado por três momentos principais: o setor expositivo sobre a Memória, nos dois andares mais altos, e o espaço dedicado à Tolerância, no terceiro pavimento. Entre eles, um pequeno e inusitado espaço transicional, um cubo opaco suspenso em meio ao átrio central.

Os arquitetos descrevem como principal desafio justamente a definição do programa temático, de forma a responder a uma transição linear dos tópicos organizados, segundo definição um tanto hiperbólica, para resultar em um "Manifesto Formal" (ARDITTI, 2010).

${ }^{5}$ Defronte à histórica Alameda Central, implantada no final do século XVI, o conjunto integra a nova sede da Secretaria de Relações Exteriores do México e o Tribunal Superior de Justiça do DF.

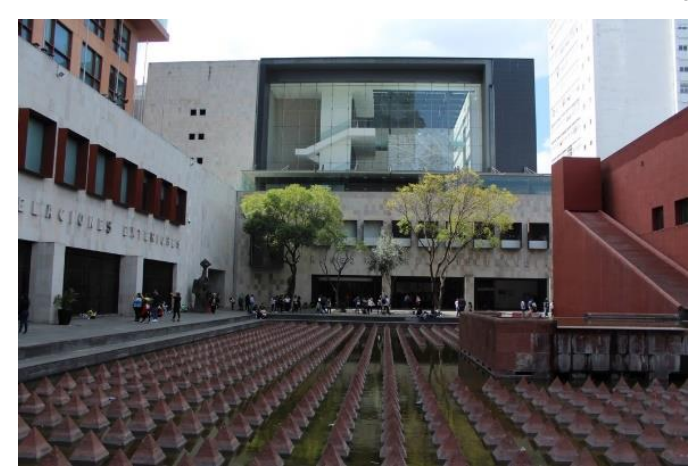

Figura 7. MyT: vista do museu a partir da praça interna ao conjunto, com a obra do artista Vicente Rojo em primeiro plano. Fonte: Ivo Giroto, 2020.

Há na lógica organizativa do museu uma evidente racionalidade, aparente inclusive nos diferentes materiais que revestem os volumes dos principais setores funcionais - madeira no auditório, granito escuro na administração, concreto aparente nas salas expositivas, Corian branco na caixa suspensa.

A espacialidade é dominada pela presença do cubo que parece flutuar no vazio, contornado pelas lâminas brancas sobrepostas da circulação horizontal, que rodeiam o vão central (Figura 8)

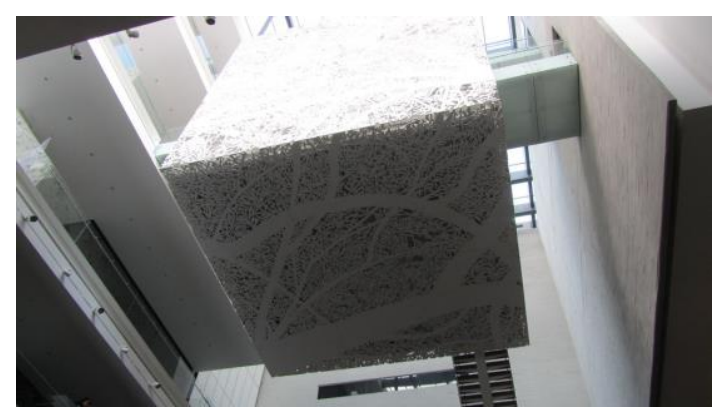

Figura 8. MyT: o cubo suspenso serve como espaço de transição entre os temas e tempos da exposição. Disponível em: https://search.creativecommons.org/photos/86aa049c-9e34-4b699a61-bc754f7f8e23. Acesso em: 20 mar 2021. 
Se por um lado a lógica racional que organiza o edifício atende bem aos requisitos funcionais e museográficos, por outro a espacialidade gerada lembra a genérica ambientação de um espaço comercial ou prédio corporativo, marcada por grandes superfícies revestidas em detrimento de uma exploração mais sutil das texturas, dos materiais, e de sua interação com a luz zenital. Parece faltar a comunicação emocional imediata com a percepção, a atmosfera que define a arquitetura como espaço envolvente (ZUMTHOR, op. cit., p. 64)

No entanto, é importante reconhecer que no MyT a racionalidade não resulta em previsibilidade. Com efeito, Barry Bergdoll (2016) reconhece entre as maiores virtudes do museu o equilíbrio alcançado entre sua estruturação lógica e o caráter labiríntico de sua circulação, que estimula o descobrimento.

Enquanto no MMDH é possível compreender a articulação geral do espaço interior com um golpe de vista, no MyT a impressão de entendimento do todo que sugere o grande espaço central é desfeita pela sucessão de espaços inesperados, que só se descortinam à medida em que são percorridos. No mesmo sentido, se o cubo acristalado do museu chileno expõe-se sem mistérios, o mexicano só revela suas entranhas quando atravessado. (Figura 9).

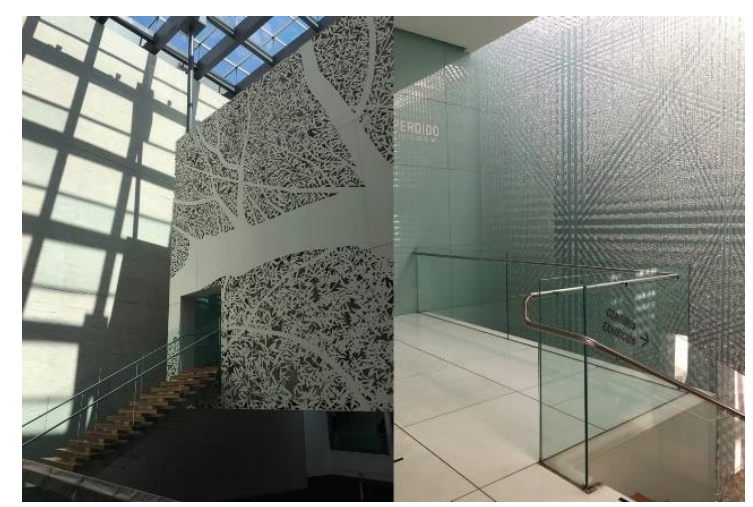

Figura 9. Obra Lamento, de Jan Hendrix. Fonte: Ivo Giroto (montagem), 2020.

No interior, uma referência ao horror maior dentro do horror: o extermínio de milhões de crianças nos maiores genocídios do século XX. O lamento pelo potencial perdido é simbolizado por uma cascata de "lágrimas" composta por 20.000 peças irregulares de vidro, cada uma representando 100.000 mortes. No exterior, o revestimento alude aos galhos e folhas de uma oliveira, símbolo da paz. Por dentro a memória dos desaparecidos, por fora o requerimento de tolerância. Em todas as dimensões, a obra Lamento, do artista mexicano de origem holandesa Jan Hendrix, utiliza cores claras, transparências e uma perspicaz exploração da luz zenital para invocar a imaterialidade e o aspecto flutuante e fantasmagórico das memórias

Outras intervenções artísticas fazem o complemento, e o contraponto, ao conteúdo informativo e figurativo que predomina na exposição. Entre as diversas obras de arte expostas no museu, destaca-se a intervenção da artista mexicana Helen Escobedo (1934-2010), notável por seu trabalho com a dimensão da memória e da experiência, e que colaborou em mais de uma ocasião com Mathias Goeritz. Sua instalação para o MyT trabalha diretamente sobre a percepção ao criar um espaço vertical introspectivo no qual uma plataforma superior sobe e baixa continuamente, gerando sensações de opressão e libertação.

Opostamente à arquitetura, que define um bom suporte à narrativa expográfica, a museografia opta pela criação de ambientes onde textos, fotografias, cartazes, depoimentos, vídeos e documentos estão dispostos em salas cuja tematização por vezes soa excessiva. Abundam paramentos ostensivamente coloridos ou adesivados com imagens, iluminação cênica, reproduções que remetem a ambientes "originais", como cercas e degraus em madeira, paredes texturizadas com arame farpado, e experiências imersivas com o uso de óculos de realidade virtual.

O museu ostenta até mesmo um vagão polonês que foi utilizado para o transporte de vítimas aos campos de concentração e um pedaço do muro de Berlim, objetosfetiche que têm seu caráter de "relíquia" enfraquecido em meio à sobreposição de estímulos visuais (Figura 10).

Com acerto, Bergdoll (ibidem) observa que as mostras prestam pouca atenção à importância que a diáspora judia teve na construção do México contemporâneo, porém é importante notar que a seção que trata da tolerância trata exclusivamente de problemas atuais, como o preconceito racial, sexual e de gênero, ou a disseminação de notícias falsas e dos discursos de ódio. 


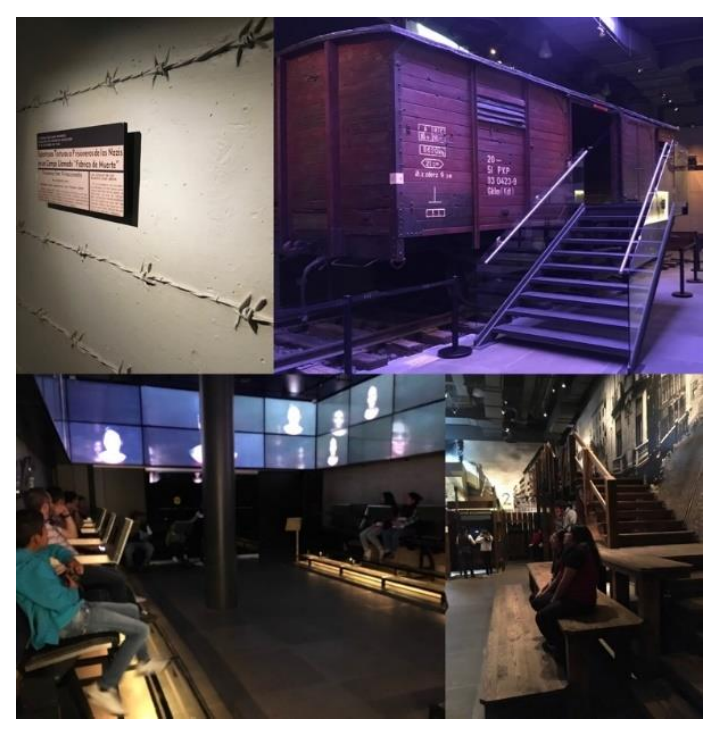

Figura 10. MyT: aspectos da museografia e detalhes da tematização das salas expositivas. Fonte: Ivo Giroto (montagem), 2020.

Excessos e lacunas à parte, ao tratar das intolerâncias no presente a narrativa museográfica alerta para o fato de que no passado serviram de suporte social à prática dos crimes contra a humanidade abordados pelo museu. Dessa forma, evita a leitura de que tais atrocidades são fatos intempestivos ou exceções irrepetíveis, ao contrário, esclarece que só podem florescer no solo fértil das culturas que banalizam cotidianamente o mal.

\section{Conclusão: narrar para emocionar, emocionar para agir}

Como visto, o caráter narrativo inerente aos museus de memória traumática é inseparável de seus propósitos institucionais e, por conseguinte, também de suas formas de representação. Muito utilizada ao longo do texto, a ideia de narrativa retorna em sua conclusão como forma de reiterar seu papel central e estabelecer uma nova relação.

Martha Nussbaum (2008, p. 272) reconhece nas emoções uma estrutura narrativa, e afirma que as obras de arte narrativas de diferentes tipos (musicais, visuais, literárias) proporcionam informação sobre histórias de emoções que de outro modo dificilmente obteríamos. Para ela, este tipo de obra de arte - ao qual pode-se agregar a arquitetura- não se limita a representar a história, senão que nela se introduz.

A dimensão narrativa atravessa, dessa maneira, a autonomia da obra de arte e também do objeto arquitetônico à medida em que é instrumento importante no processo de compreensão das emoções, auxiliando na elaboração do sofrimento individual e na capacidade de ver a outras pessoas de uma forma não instrumental (NUSSBAUM, 2008, p. 273).

No mesmo sentido, para além de oferecer um lugar para o luto, o principal propósito de um museu que trate de memórias traumáticas é criar um recordatório permanente para evitar que crimes análogos aos abordados voltem a ocorrer. Com efeito, a raiz etimológica latina da palavra monumento - moneo, monere- refere-se tanto a lembrar quanto a alertar.

Ulpiano Bezerra de Meneses (op. cit., p. 8) defende que o museu não deve apenas esclarecer traumas antigos, mas despertar a capacidade de desnaturalizar o passado para também desnaturalizar o presente, colocando os visitantes diante de sua responsabilidade como sujeitos da história.

Portanto, parece mais frutífera uma abordagem da dor que enfatize a dimensão de atualidade inerente aos crimes do passado e privilegie dinâmicas de empatia coletiva com as vítimas, de forma a evitar a privatização da memória histórica. Muitos estudiosos alertam para os riscos de fetichização das atrocidades e do sofrimento das vítimas, o que poderia até mesmo causar um efeito inverso ao desejado: a homogeneização e a universalização das dores (WILLIAMS, op. cit.).

Para arquitetura e museografia, o desafio está na dificuldade de encontrar uma forma de representação de eventos dolorosos de maneira que sirvam como espaços coletivos para o luto e como suportes para a reflexão política. O conteúdo emocional inerente a museus como os analisados encontra rebatimentos no campo da História a partir da abordagem fenomenológica desenvolvida por autores como David Carr (2017), que ao tratar das complexas relações da experiência com as dimensões da historicidade e da narrativa encontra na base de toda ação humana o campo comum à arte e à vida.

De forma análoga, Paul Ricoeur (2007, p. 71) defende que a ação é inerente ao ato de lembrar, que não deve ser somente acolher, receber uma imagem passada, mas 
também buscá-la, 'fazer' alguma coisa com ela. No museu, coincide com o propósito de tocar emocionalmente os visitantes para estimulá-los a agir, como observou Meneses.

A resposta parece estar em formas de representação, arquitetônica e museográfica, que reforcem o propósito do museu a partir de uma abordagem que trabalhe o espaço não como o ambiente em que as coisas se dispõem, mas como o meio pelo qual a posição das coisas se torna possível a partir da potência universal de suas conexões (MERLEAU-PONTY, op. cit. p. 328). Estas vinculações - sentimentais e políticas, individuais e coletivas - podem ser provocadas pelo que Juani Pallasma (2006, p 11) define como arte e arquitetura significativas, aquelas capazes de provocar experiências nos sujeitos como seres espirituais e corporais a fim de emancipar suas percepções e ideias.

Analisados lado a lado, MMDH e MyT demonstram o quão delicado é o trabalho de musealizar tragédias e atrocidades. Ao fazer uma crítica norteada pela exploração da emoção e da experiência, o artigo reconhece a dimensão desta dificuldade e não quer assumir - como nem o museu deve querer - o papel de juiz a proferir sentenças definitivas. Mesmo porque os campos emocional e experiencial não são generalizáveis ou redutíveis a interpretações totalizadoras. As reflexões do texto buscaram indagar sobre como tais estratégias são estruturadas em cada caso, bem como apontar os possíveis limites de sua utilização à luz dos propósitos institucionais a que correspondem. Ou, nas palavras de Graciela Silvestri (2013, p. 23), investigar sua capacidade de responder ao programa "sem solenidades nem estridências".

Ao fim e ao cabo, as estratégias emocionais utilizadas pela arquitetura e pela museografia para a representação de crimes contra a humanidade não podem ser a mera reencenação de traumas, mas abrir passo a possibilidades contemporâneas de negociação entre pessoas que desejam um futuro diferente (GREENBERG, 2010, p. 7). Recuperando Nora, a memória do passado é vivida no presente para informar o futuro. Tampouco se pode esquecer que a memória pode ser evocada, mas os fatos não podem ser revividos ou, como diz o ditado: recordar é viver, e não reviver.

\section{Referências}

ABBAGNANO, N. Dicionário de Filosofia. São Paulo: Mestre Jou, 1970.

ARANTES, Otília. O lugar da arquitetura depois dos modernos. São Paulo: Edusp, 1993.

ARDITTI + RDT. Museo Memoria y Tolerancia. ArchDaily México, nov. 2010. Disponível em: https://www.archdaily.mx/mx/02-59649/museo-memoria-y-toleranciaardittirdt-arquitectos. Acesso em: 14. Fev. 2021.

ARNOLD-DE-SIMINE, Silke, Is there such a thing as "collective memory"?, In: Mediating memory in the museum. Trauma, empathy and nostalgia. Londres: Palgrave Macmillan, 2013, p.20-21.

BACHELET, Michele. Dicurso de S.E. la presidenta de la república Michelle Bachelet en inauguración del Museo de la Memoria y los Derechos Humanos. Dirección de Prensa - Republica de Chile, Santiago, 11 jan. 2010. Disponível em: $<$ https://ww3.museodelamemoria.cl/wp-content/uploads/2016/01/discurso-presidenta.pdf>. Acesso em: 05 jan. 2021.

BERGDOLL, Barry. Un marco para reescenificar la memoria. Arquine, Cidade do México, 18 oct. 2016. Disponível em: https://www.arquine.com/un-marco-para-reescenificar-la-memorial. Acesso em: 15 fev. 2021.

BOTERO, Juan David. Museu Casa de la Memoria / Juan David Botero. ArchDaily Brasil, set. 2015. Disponível em: https://www.archdaily.com.br/br/773399/museucasa-de-la-memoria-juan-david-botero. Acesso em: 11 fev. 2021.

BRESCIANI, Stella; NAXARA, Márcia (orgs). Memória e (res)sentimento: indagações sobre uma questão sensível. 2. ed. Campinas: Editora da Unicamp, 2004.

BARCLAY, Sandra; CROUSSE, Jean-Pierre. Lugar de memória. ArchDaily Brasil, jun 2015. Disponível em: https://www.archdaily.com.br/br/760919/lugar-de-la-memoria-barclay-and-crousse. Acesso em: 05 mar. 2021. 
BASTÍAS SEKULOVIC, Malena. Del relato oficial a la recepción de los visitantes: análisis de la puesta en escena del pasado reciente en el Museo de la Memoria y de los Derechos Humanos de Chile. In: URTIZBEREA, Arrieta (Ed.). Lugares de memoria traumática: representaciones museográficas de conflictos políticos y armados Bilbao: Universidad del País Vasco, 2017, p. 199-219.

BAUDET, Ricardo Brodsky. Memoriales, monumentos, museos: memoria, arte y educación em los derechos humanos. Lua Nova, São Paulo, n. 96, p. 149-161, dez. 2015. Disponível em: http://www.scielo.br/scielo.php?script=sci_arttext\&pid=S010264452015000300009\&lng=en\&nrm=iso. Acesso em: 25 fev. 2021.

CYMBALISTA, Renato. $\mathbf{O}$ guia dos lugares difíceis de São Paulo. São Paulo: Annablume, 2018.

CABRAL, Rebeca Lopes. Memórias de dor em Buenos Aires: de ex-centros clandestinos a lugares de memória e consciência. Dissertação (mestrado), Faculdade de Arquitetura e Urbanismo, Universidade de São Paulo, São Paulo, 2019.

CARR, David. Experiencia e historia: perspectivas fenomenológicas sobre el mundo. Buenos Aires: Prometeo, 2017.

CHOAY, Françoise. A alegoria do patrimônio. 6 ed. São Paulo: Estação Liberdade: Ed. UNESP, 2017.

CONNERTON, Paul. How Societies Remember. Cambridge: Cambridge University Press, 1989.

. How Modernity Forgets. Cambridge: Cambridge University Press, 2009.

CONSIDERA, Andréa Fernandes. Direito à memória e museus. Museologia \& Interdisciplinaridade, Brasília, vol. 4, n 8, p. 147-157, dez. 2015.

CUNDY Alys; PÖRZGEN, Yvonne. Emotional Strategies in Museum Exhibitions. Museum \& Society, Leicester, 14 (3), p. 359-362, nov. 2016. Disponível em: https://journals.le.ac.uk/ojs1/index.php/mas/article/view/650/607?acceptCookies=1. Acesso em: 13 jan. 2021.
ESTEFANE, Andres. Materiality and Politics in Chile's Museum of Memory and Human Rights. Thresholds, n 41, p. 158-171, primavera 2013. Disponível em: https://direct.mit.edu/thld/article/doi/10.1162/thld a 00107/56645/Materiality-andPolitics-in-Chile-s-Museum-of. Acesso em: 07 fev. 2021.

FIGUEROA, M.; FEHR, L.; DIAS, C. El concepto. In: Museo de la memoria y los derechos humanos. Santiago: MMDH, 2010, p. 34-45.

GREENBERG, Reesa. La représentation muséale des génocides. Gradhiva, Paris, n. 5, mai. 2010. Disponível em : http://journals.openedition.org/gradhiva/758. Acesso em: 09 fev. 2021.

GOERITZ, Mathias. Manifiesto de la arquitectura emocional, 1953. Museo Experimental el Eco, Cidade do México, jul. 2015. Disponível em: https://eleco.unam.mx/manifiesto-de-la-arquitectura-emocional-1953/. Acesso em: 02 mar. 2021.

HALBWACHS, Maurice. A memória coletiva. 2 ed. São Paulo: Centauro, 2013.

HANSEN-GLÜCKLICH, Jennifer. Poetics of Memory: Aesthetics and Experience of Holocaust Remembrance in Museums. Dapim: Studies on the Holocaust, Haifa, 2016, vol. 30, n. 3, p. 315-334, out. 2016.

HOWES, David. Introduction to sensory museology. The senses and society, Londres: Bloomsbury Publishing, vol. 9, n. 3, pp. 259-267, 2014.

HUYSSEN, Andreas. Seduzidos pela memória: arquitetura, monumentos, mídia. Rio de Janeiro: Aeroplano, 2000.

LANDSBERG, A. Prosthetic Memory: The Transformation of American Remembrance in the Age of Mass Culture. New York: Columbia University Press, 2004.

LAVIELLE, Julie. Musealizar el pasado y el presente de la violencia. Un estudio de las percepciones de los visitantes del Museo Casa de la Memoria de Medellín. Desafios, 32(2), p. 1-39, 2020. Disponível em: https://www.doi.org/10.12804/ revistas.urosario.edu.co/desafios/a.8186. Acesso em: 05 jul. 2021.

LAWNER STEIMAN, Miguel. Uma manzana abierta. In: Museo de la memoria y los derechos humanos. Santiago: MMDH, 2010, p. 11-15. 
LIFSCHITZ, Javier Alejandro. Os agenciamentos da memória política na América Latina. RBCS, São Paulo, vol. 29, n 85, p. 145-225, jun. 2014.

LE GOFF, Jacques. História e memória. Campinas: Editora da Unicamp, 1990.

MENESES, Ulpiano Bezerra de. Os museus e as ambiguidades da memoria: a memoria traumática. In: 10 Encontro Paulista de Museus-SISEM, p. 1-16, jul. 2018, São Paulo. Disponível em: https://www.sisemsp.org.br/wp-content/uploads/2018/08/Ulpiano-Bezerra-de-Meneses.pdf. Acesso em: 12 jan. 2020.

MERLEAU-PONTY, Maurice. Fenomenologia da percepção. 4 ed. São Paulo: Martins Fontes, 2011.

MORA HERNÁNDEZ, Y. (2013). Lugares de memoria: entre la tensión, la participación y la reflexión. Panorama, [S.I], vol 7, n 13, p. 97-109. Disponível em: https://doi.org/10.15765/pnrm.v7i13.434. Acesso em: 26 jan. 2021.

NORA, Pierre (org). Les lieux de mémoire. Paris: Gallimard, 1984.

. Entre memória e história: a problemática dos lugares. Projeto História, São Paulo, n. 10, p. 7-28, dez. 1993.

NUSSBAUM, Martha C. Paisajes del pensamiento: la inteligencia de las emociones. Barcelona: Paidós, 2008.

PALLASMA, Juani. Los ojos de la piel. La arquitectura y los sentidos. Barcelona: Gustavo Gili, 2006.

POLLAK, Michael. Memória, esquecimento e silêncio. Estudos Históricos. Rio de Janeiro: CPDOC, vol.2, n. 3, p.3-15, 1989.

RAMÍREZ NIETO, Jorge. Crítica, critérios y tendências. Observatorio de arquitectura latinoamericana contemporánea, texto inédito, 2011.

RICOEUR, Paul. A memória, a história, o esquecimento. Campinas: Unicamp, 2007.

SARLO, Beatriz. Tiempo pasado: cultura de la memoria y giro subjetivo. Una discusión. Buenos Aires: Siglo veintiuno, 2003.

SILVESTRI, Graciela. El arte en los límites de la representación. Punto de Vista, Buenos Aires, n. 68, p. 18-24, dez. 2000.
STURKEN, Marita. Comfort, Irony, and Trivialization: The Mediation of Torture. International Journal of Cultural Studies (Special Issue in Tribute to Roger Silverstone), Londres: SAGE, pp. 1-18, 2011.

. The 9/11 Memorial Museum and the Remaking of Ground. ZeroAmerican Quarterly, Nova lorque: New York University, vol. 67, n. 2, pp. 471-490, jun. 2015.

TODOROV. Los usos de la memoria. Santiago: Museo de la memoria y de los derechos humanos, 2013.

TORRE, Susana. Ciudad, memoria y espacio público: el caso de los monumentos a los detenidos y desaparecidos. Memoria y Sociedad, Bogotá, Vol. 10, n. 20, p. 17-24, jan-jun. 2006. Disponível em: https://revistas.javeriana.edu.co/index.php/memoysociedad/article/view/8118. Acesso em: $18 \mathrm{dez} .2020$.

VILLAC, Maria Isabel. La construcción de la mirada. Naturaleza, ciudad y discurso en la arquitectura de Paulo Archias Mendes da Rocha. Tese (Doutorado em Teoria e História da Arquitetura) - Escuela Técnica Superior de Arquitectura de Barcelona, Universidad Politécnica de Cataluña, Barcelona, 2002.

ZUMTHOR, Peter. Atmosferas. Entornos arquitectónicos - as coisas que me rodeiam. 1 ed. Barcelona: Gustavo Gili, 2009.

WILLIAMS, Paul. Memorial Museums: The Global Rush to Commemorate Atrocities. Oxford: Berg, 2007. 